\title{
Mechanistic modeling of cutting forces in high-speed microturning of titanium alloy with consideration of nose radius
}

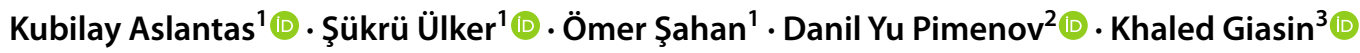

Received: 26 August 2021 / Accepted: 23 November 2021 / Published online: 10 December 2021

(c) The Author(s) 2021

\begin{abstract}
Microturning is a micromechanical machining process used to produce microcylindrical or axially symmetrical parts. Microcylindrical parts are mainly used in microfluidic systems, intravenous micromotors, microsurgical applications, optical lens applications, and microinjection systems. The workpiece diameter is very small in microturning and therefore is greatly affected by the cutting forces. For this reason, it is important to predict the cutting forces when machining miniature parts. In this study, an analytical mechanistic model of microturning is used to predict the cutting forces considering the tool nose radius. In the semi-empirically developed mechanistic model, the tool radius was considered. A series of semi-orthogonal microturning cutting tests were carried out to determine the cutting and edge force coefficients. The mechanistic model was generalized depending on the cutting speed and depth of cut by performing multilinear regression analysis. In the study, the depth of cut $\left(a_{p}=30-90 \mu \mathrm{m}\right)$ and feed values $(f=0.5-20 \mu \mathrm{m} / \mathrm{rev})$ were selected considering the nose radius and edge radius of the cutting tool. The experiments were carried out under high-cutting speeds $\left(V_{c}=150-500 \mathrm{~m} / \mathrm{min}\right)$ and microcutting conditions. Ti6A14V alloy was used as the workpiece material and the tests were carried out under dry cutting conditions. Validation tests for different cutting parameters were carried out to validate the accuracy of the developed mechanistic model. The results showed that the difference between the mechanistic model and the experimental data was a minimum of $3 \%$ and a maximum of $24 \%$. The maximum difference between the experimental and the model usually occurs in forces in the tangential direction. It has been observed that the developed model gives accurate results even at a depth of cut smaller than the nose radius and at feed values smaller than the edge radius.
\end{abstract}

Keywords Microturning $\cdot$ High-speed cutting $\cdot$ Mechanistic modeling $\cdot$ Cutting forces $\cdot$ Nose radius $\cdot$ Ti6Al4V alloy

Khaled Giasin

khaled.giasin@port.ac.uk

Kubilay Aslantas

aslantas@aku.edu.tr

Şükrü Ülker

ulker@aku.edu.tr

Ömer Şahan

omer@afyonkarahisartso.org.tr

Danil Yu Pimenov

danil_u@rambler.ru

1 Department of Mechanical Engineering, Afyon Kocatepe University, Afyonkarahisar, Turkey

2 Department of Automated Mechanical Engineering, South Ural State University, Lenin Prosp. 76, Chelyabinsk 454080, Russia

3 School of Mechanical and Design Engineering, University of Portsmouth, Portsmouth PO1 3DJ, UK

$\begin{array}{ll}\begin{array}{l}\text { Abbreviations } \\ \text { Ft, Fr, Ff } \\ \text { Fxexp, Fyexp, Fzexp, }\end{array} & \begin{array}{l}\text { Tangential, radial, feed force (N) } \\ \text { Experimental cutting force from } \\ \text { microturning tests (N) } \\ \text { Elemental tangential, radial, feed } \\ \text { force }(\mathrm{N})\end{array} \\ \mathrm{CH}, \mathrm{dFr}, \mathrm{dFf} & \text { Chip section (i:I, II) (mm2) } \\ \mathrm{Ai} & \text { Material removal rate } \\ \mathrm{MRR} & \text { Hardness Rockwell C (MPa) } \\ \mathrm{HRC} & \text { Cutting length (i: I, II) (mm) } \\ \mathrm{Li} & \text { Cutting force coefficients }(\mathrm{N} / \\ \mathrm{Ktc}, \mathrm{Kfc}, \mathrm{Krc} & \text { mm2) } \\ \mathrm{Kte}, \mathrm{Kfe}, \mathrm{Kre} & \text { Edge force coefficients (N/mm) } \\ \text { ap } & \text { Depth of cut (mm) } \\ \mathrm{Vc} & \text { Cutting speed }(\mathrm{m} / \mathrm{min}) \\ \mathrm{h}(\mathrm{q}) & \text { Chip thickness }(\mathrm{mm}) \\ \mathrm{f} & \text { Feed rate }(\mathrm{mm} / \mathrm{rev}) \\ \mathrm{Re} & \text { Nose radii }(\mu \mathrm{m}) \\ \mathrm{Re} & \text { Tool edge radius }(\mu \mathrm{m})\end{array}$




$\begin{array}{ll}\mathrm{kr} & \text { Cutting edge angle }\left(^{\circ}\right) \\ \mathrm{krm} & \text { Minor cutting edge angle }\left(^{\circ}\right) \\ \mathrm{dL} & \text { Elemental edge length }(\mathrm{mm}) \\ \mathrm{q} & \text { Angle made by positive X-axis }\left(^{\circ}\right) \\ \mathrm{q} 1, \mathrm{q} 2 & \text { Limits of integration }\left(^{\circ}\right) \\ \text { Fx, Fy, Fz } & \begin{array}{l}\text { Total cutting force at tangential, } \\ \text { radial, and feed directions, respec- } \\ \text { tively (N) }\end{array} \\ \text { Gij, Zij } & \text { Tool geometry and cutting condi- } \\ \text { tions expressions }\end{array}$

\section{Introduction}

Nowadays, the miniaturization of components plays an important role in various application areas such as biomedical, electronics, aerospace, and communications. Microcomponents with cylindrical geometry are mainly used in microfluidic systems, intravenous micromotors, microsurgical applications, optical lens applications, and microinjection systems. The most used technique in the manufacturing of cylindrical microgeometries is microturning. Microturning is a process that belongs to micromechanical machining processes and is used to manufacture microcylindrical or axially symmetrical parts [1]. The most important advantage of microturning is that three-dimensional parts can be easily formed at high speeds. However, the metal removal rate can vary depending on the equipment and cutting tool used. The most critical disadvantage of microturning is that the cutting force affects the machining accuracy [2]. Due to the low diameter-to-length ratio, the workpiece is forced to vibrate in the tangential direction while the cutting tool supports the workpiece, which helps to reduce the vibration [3]. Therefore, by controlling the cutting forces in microturning, more accurate and smaller parts can be produced [4]. A significant problem that occurs during cutting is the elastic deflection of the workpiece. To achieve the lowest possible elastic deflection in microturning, the cutting forces must also be small. Various methods are proposed to eliminate the elastic deflection of the workpiece [5]. To predict the elastic deflection that may occur in microturning, the cutting forces must be known. Cutting forces can be estimated using a variety of modeling techniques as well as experimental methods. Numerical modeling and mechanistic modeling are the most used methods for estimating cutting forces. It is possible to come across studies on turning [6-8], milling $[9,10]$, and drilling [11] processes using numerical modeling techniques. It is also possible to come across studies in which the mechanistic model is used to predict cutting forces in orthogonal turning [12], conventional turning [13], and milling $[14,15]$ operations. In a study in which the mechanistic model and finite element analysis were used together, the estimation of the cutting forces in the microturning process was carried out [16]. Although Ti6Al4V alloy was used in this study, the cutting speed values were chosen very low.

Ti6Al4V alloy offers superior properties in terms of strength, corrosion resistance, and biocompatibility and is widely used in implant manufacturing. Ti6Al4V alloy, also called grade 5, is classified as difficult to machine materials. The main problems in micromachining of these alloys are rapid tool wear [17, 18], burr formation [19], and built-up edge [20]. Chip adhesion and consequently the poor surface quality and tool breakage are among the most encountered problems, especially in the micromilling of Ti6Al4V alloy. When turning the Ti6Al4V alloy at medium cutting speeds (30-60 $\mathrm{m} / \mathrm{min}$ ), while the tool life is longer, chip adhesion and long chip formation problems may occur. Tool wear is the biggest problem at high cutting speeds $(>120 \mathrm{~m} / \mathrm{min})$. High-speed machining results in better surface finish and lower cutting force, while increasing efficiency in metal removal. In addition to these advantages, machining at high speed causes an increase in the cutting temperature in the cutting zone. As a result, tool wear increases, and tool life is shortened. To overcome the high temperature produced during high-speed machining, cutting fluids are used. Highspeed machining means that the strain rate increases. As a result, not only the cutting forces change but also the chip shape and tool-chip contact conditions. In the studies carried out for high-speed turning of Ti6Al4V alloy, the cutting speed was taken as a maximum of $150 \mathrm{~m} / \mathrm{min}[21,22]$. Aslantas et al. [23], the cutting speed was used between 100 and $400 \mathrm{~m} / \mathrm{min}$. In the study, it is recommended to choose a high cutting speed for maximum metal removal rate (MRR) and minimum surface roughness. In another study by Aslantas and Cicek [24], ultra-high cutting speeds (1250 m/ min) were used. The authors state that the cutting forces remain constant at cutting speeds greater than $1000 \mathrm{~m} / \mathrm{min}$.

In the conventional turning process, the mechanistic modeling technique is commonly used for force estimation. However, studies using the mechanistic modeling technique in the microturning process are quite recent. The microturning process is defined by several key characteristics: high speed, low depth of cut, low feed rate, relatively large tool nose radius, and tool edge radius. These characteristics lead to a different chip forming mechanism and force generation 
compared to conventional turning. It has been stated that the thrust force is greater than the tangential force at a very low depth of cut [25]. It has been emphasized that the direction of the resulting force vector changes significantly undercutting conditions where the thickness of the undeformed chip is smaller than the edge radius [26]. Horvart estimated the cutting forces in the fine-tuning process using a new force model. In the study, a specific cutting force was determined considering the radius of the tool nose radius [27]. Jagadesh and Samuel [16] developed a mechanistic model to predict the cutting forces in microturning. In the study, the verification of the mechanistic model was carried out using the finite element technique. The finite element method is also used to obtain the coefficients used in mechanistic modeling [28]. In this study, full orthogonal shear experiments were carried out under microconditions. The shear and edge force coefficients obtained were compared with the numerical modeling results. Jin and Altintas [29] used a slip-line field model that considers the stress variation in the material deformation zone due to the tool edge radius effect. The total cutting forces are evaluated by integrating the forces along the entire contact zone between the chip and the rake face and the plowing force caused by the round cutting edge. The proposed model was experimentally verified by a series of cutting force measurements performed during microturning tests. Based on Merchant's analysis of 3D cutting, Shalaby et al. [30] developed a mechanistic force model in which the depth of cut is much smaller than the tool tip radius. Both the tool tip radius and the flank wear occurring in the tool were considered in the model created.

To date, many studies have been conducted to estimate the cutting force in the turning process, and the majority of these studies have considered the conventional cutting process. In recent years, it is possible to come across studies on modeling cutting forces in microturning. However, in these studies, the cutting speeds investigated were in the low range. For this reason, none of the previous studies employed mechanistic

modeling at very high cutting speeds for Ti6Al4V alloy. From this point of view, this study aims to fill this gap in the literature. In addition, it has been shown that the mechanistic model can be generalized depending on the cutting speed and depth of cut, and it can be used for different cutting parameters by performing multilinear regression analysis.

\section{Modelling of cutting forces}

\subsection{Geometrical modeling}

To model the cutting force in the microturning process, geometric modeling should be done first. In microturning, the nose radius, cutting edge angle, the depth of cut, and the feed rate of the cutting tool are required for geometric modeling. This is because these four factors directly affect the chip cross-section. For a healthy cutting process in microturning, it is generally recommended that the depth of cut should be greater than the nose radius and the feed value should be greater than the tool's edge radius [25]. In the mechanistic model used in this study, the depth of cut is greater than the nose radius $\left(a_{p}>R_{\varepsilon}\right)$, and the cutting edge angle $\kappa_{\mathrm{r}}=90^{\circ}$ is considered.

In Fig. 1, uncut chip thickness is constant in region II and depends on the feed rate $(f)$ and the cutting-edge angle $\left(\kappa_{r}\right)$. In this region, the magnitude and direction of the forces along the straight edge $\left(a_{p}-R_{\varepsilon}\right)$ do not change. The cutting-edge length $\left(L_{I I}\right)$ and the chip cross-sectional area $\left(A_{I I}\right)$ in this range are obtained from Eqs. (1, 2, 3, 4 and 5).

$$
\begin{aligned}
& L=\frac{a_{p}}{\sin \kappa_{r}} \\
& h=f \cdot \sin \kappa_{r} \\
& A=L \cdot h=a_{p} . f
\end{aligned}
$$

Fig. 1 Definition of the tool geometry during microturning operation. a Top view of the turning process. b Geometric definitions of the nose radius
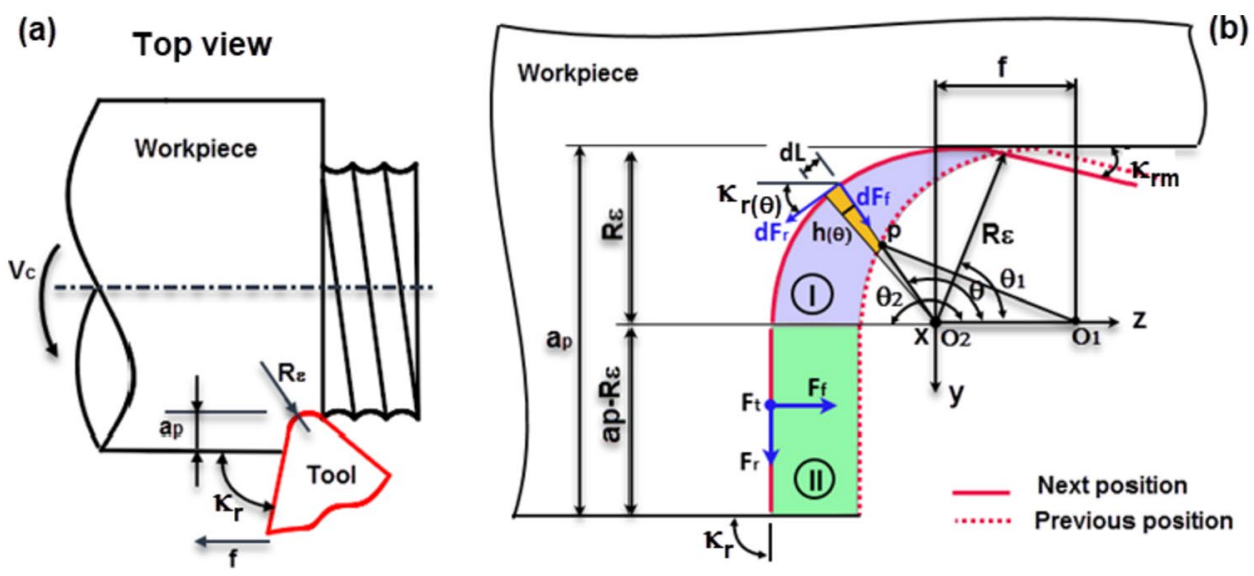
$L_{I I}=\frac{a_{p}-R_{\varepsilon}\left(1-\cos \kappa_{r}\right)}{\sin \kappa_{r}}$

$A_{I I}=f \cdot\left[a_{p}-R_{\varepsilon}\left(1-\cos \kappa_{r}\right)\right]-\frac{1}{4} f^{2} \sin \left(2 \kappa_{r}\right)$

where $a_{p}$ is the depth of cut, $\kappa_{r}$ is the cutting-edge angle, $f$ is the feed rate, $h$ is the chip thickness, and $R_{\varepsilon}$ is the nose radius. Chip thickness in the first region constantly changes. However, the direction and magnitude of the cutting forces also change. As can be seen in Fig. 1, the chip thickness in the first region is expressed as an infinitesimal element. In addition, the forces occurring in the infinitesimal element are shown as $d F_{t}, d F_{r}$, and $d F_{f}$. The direction of each infinitesimal force is considered normal with respect to the local cutting edge. The edge length $\left(L_{I}\right)$ and chip cross section $\left(A_{I}\right)$ of the chip in the first region can be calculated as follows.

$L_{I}=\int_{\theta_{1}}^{\theta_{2}} d L=\int_{\theta_{1}}^{\theta_{2}} R_{\varepsilon} d \theta$

$A_{I}=\int_{\theta_{1}}^{\theta_{2}} h(\theta) d L=\int_{\theta_{1}}^{\theta_{2}} h(\theta) R_{\varepsilon} d \theta$

where integration limits $\theta_{1}$ and $\theta_{2}$ are given by the expressions in Eq. (8).

$\theta_{1}=\cos ^{-1} \frac{f}{2 R_{\varepsilon}}, \theta_{2}=\frac{\pi}{2}+\kappa_{r}$

To calculate the chip cross-sectional area given in Eq. (8), it is necessary to determine the chip thickness. The chip thickness in zone II varies as a function of $\theta$. In turning processes where the nose radius is considered, the chip thickness can be determined obtained by using the geometric relationship in the triangle $\mathrm{pO}_{1} \mathrm{O}_{2}[31]$.

$h(\theta)=R_{\varepsilon}-\sqrt{f^{2}+R_{\varepsilon}{ }^{2}-2 f R_{\varepsilon} \cos \left[\pi-\theta-\sin ^{-1}\left(\frac{f}{R_{\varepsilon}} \sin (\theta)\right)\right]}$

\subsection{Mechanistic modelling}

The model proposed in this study allows the estimation of the cutting forces in the microturning process considering the cutting-edge angle and the nose radius. The mechanistic model presented here is based on the statements proposed by Altıntaş [32]. This model divides the cutting forces into two main components. The first is the force generated by the sliding mechanism, which is proportional to the cross section of the chip that has not been cut. The second is the force generated by plowing, which is proportional to the edge length of the cutter. Equation (10) gives the general expression of the mechanistic model proposed by Altıntaş.

$F_{t}=K_{t c} \cdot A+K_{t e} \cdot L$

$F_{f}=K_{f c} \cdot A+K_{f e} \cdot L$

$F_{r}=K_{r c} \cdot A+K_{r e} \cdot L$

where $F_{v}, F_{f}$ and $F_{r}$ are tangential, feed, and thrust forces, respectively. $K_{t c}, K_{f c}$, and $K_{r c}$ are called cutting force coefficients, and $K_{t e}, K_{f e}$, and $K_{r e}$ are called edge force coefficients. In zone II, which is shown in Fig. 1, the cutting edge angle does not change, and the chip cross section becomes constant. The magnitude and direction of the cutting forces in zone II also do not change. Therefore, when $L_{I I}$ and $A_{I I}$ from Eqs. (4) and (5) are substituted into Eq. (10), the cutting force components in zone II are obtained.

$F_{f I I}=K_{f c} A_{I I}+K_{f e} L_{I I}$

$F_{r I I}=K_{r c} A_{I I}+K_{r e} L_{I I}$

$F_{t I I}=K_{t c} A_{I I}+K_{t e} L_{I I}$

In zone I, the cutting edge angle $\kappa_{r(\theta)}$ constantly changes, and as a result, the direction and magnitude of the cutting forces also change. For this reason, each force component occurring in zone I can be written as follows.

$F_{f I}=\int_{\theta_{1}}^{\theta_{2}} K_{f c}(\theta) h(\theta) R_{\varepsilon} d \theta+\int_{\theta_{1}}^{\theta_{2}} K_{f e}(\theta) R_{\varepsilon} d \theta$

$F_{r I}=\int_{\theta_{1}}^{\theta_{2}} K_{r c}(\theta) h(\theta) R_{\varepsilon} d \theta+\int_{\theta_{1}}^{\theta_{2}} K_{r e}(\theta) R_{\varepsilon} d \theta$

$F_{t I}=\int_{\theta_{1}}^{\theta_{2}} K_{t c}(\theta) h(\theta) R_{\varepsilon} d \theta+\int_{\theta_{1}}^{\theta_{2}} K_{t e}(\theta) R_{\varepsilon} d \theta$

The total forces obtained during cutting are obtained by summing the force components belonging to the 1 st and 2nd zones given in Eqs. (11) and (12).

$F_{f}=F_{f I}+F_{f I I}$

$F_{t}=F_{t I}+F_{t I I}$

$F_{r}=F_{r I}+F_{r I I}$

In the turning process given in Fig. 1, the cutting-edge angle is $\kappa_{r}=90^{\circ}$. Therefore, the cutting forces occurring 
in the $x$-, $y$-, and $z$-directions in region II are equal to the tangential $\left(F_{t}\right)$, radial $\left(F_{r}\right)$, and feed $\left(F_{f}\right)$ forces, respectively (Eq. 14).

$\left[\begin{array}{c}F_{x} \\ F_{y} \\ F_{z}\end{array}\right]=\left[\begin{array}{ccc}1 & 0 & 0 \\ 0 & \sin \kappa_{r} & \cos \kappa_{r} \\ 0 & -\cos \kappa_{r} & \sin \kappa_{r}\end{array}\right]\left[\begin{array}{c}F_{t} \\ F_{r} \\ F_{f}\end{array}\right]$

By substituting the relevant forces from Eq. (13) into Eq. (14), the total cutting forces can be evaluated.

$F_{x}=F_{t I}+F_{t I I}$

$F_{y}=F_{f I} \cos \kappa_{r}(\theta)+F_{f I I} \cos \kappa_{r}+F_{r I} \sin \kappa_{r}(\theta)+F_{r I I} \sin \kappa_{r}$

$F_{z}=F_{f I} \sin _{r}(\theta)+F_{f I I} \sin \kappa_{r}-F_{r I} \cos \kappa_{r}(\theta)-F_{r I I} \cos \kappa_{r}$

where $\kappa_{r}(\theta)=\theta-\pi / 2$. By substituting the relevant forces from Eqs. (11) and (12) in Eqs. (15), (16) and (17), a transformation between cutting force components $\left(F_{t}, F_{f} F_{r}\right)$ and $\left(F_{x}\right.$, $\left.F_{y}, F_{z}\right)$ in the dynamometer's coordinate system is achieved.
$\boldsymbol{F}_{\boldsymbol{x}}=\int_{\theta_{1}}^{\theta_{2}} K_{t c}(\theta) h(\theta) R_{\varepsilon} d \theta+\int_{\theta_{1}}^{\theta_{2}} K_{t e}(\theta) R_{\varepsilon} d \theta+K_{t c} A_{I I}+K_{t e} L_{I I}$

$\boldsymbol{F}_{y}=\int_{\theta_{1}}^{\theta_{2}} K_{f c}(\theta) h(\theta) R_{\varepsilon} \cos \kappa_{r}(\theta) d \theta+\int_{\theta_{1}}^{\theta_{2}} K_{f e}(\theta) R_{\varepsilon} \cos \kappa_{r}(\theta) d \theta+K_{f c} A A_{I I} \cos \kappa_{r}$

$+K_{f e} L_{I I} \cos \kappa_{r}+\int_{\theta_{1}}^{\theta_{2}} K_{f c}(\theta) h(\theta) R_{\varepsilon} \sin \kappa_{r}(\theta) d \theta+\int_{\theta_{1}}^{\theta_{2}} K_{r e}(\theta) R_{\varepsilon} \sin \kappa_{r}(\theta) d \theta$

$+K_{r c} A_{I I} \sin \kappa_{r}+K_{r e} L_{I I} \sin \kappa_{r}$

$$
\begin{aligned}
\boldsymbol{F}_{z} & =\int_{\theta_{1}}^{\theta_{2}} K_{f c}(\theta) h(\theta) R_{\varepsilon} \sin \kappa_{r}(\theta) d \theta+\int_{\theta_{1}}^{\theta_{2}} K_{f e}(\theta) R_{\varepsilon} \sin \kappa_{r}(\theta) d \theta+K_{f c} A_{I I} \sin \kappa_{r} \\
& +K_{f e} L_{I I} \sin \kappa_{r}-\int_{\theta_{1}}^{\theta_{2}} K_{f c}(\theta) h(\theta) R_{\varepsilon} \cos \kappa_{r}(\theta) d \theta-\int_{\theta_{1}}^{\theta_{2}} K_{r e}(\theta) R_{\varepsilon} \cos \kappa_{r}(\theta) d \theta \\
& -K_{r c} A_{I I I} \cos \kappa_{r}-K_{r e} L_{I I} \cos \kappa_{r}
\end{aligned}
$$
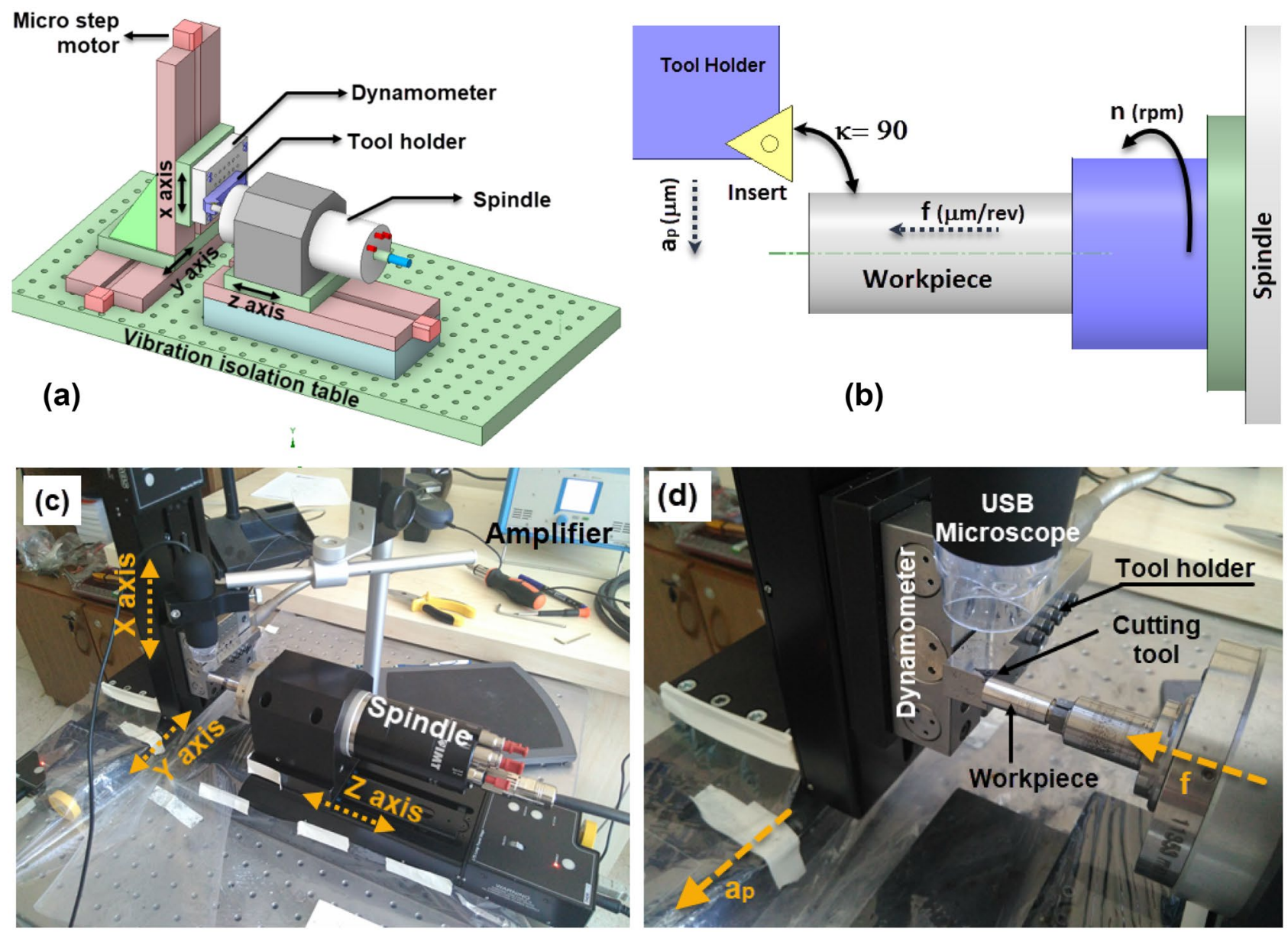

Fig. 2 a Schematic representation of the system used in microturning experiments. b Position of cutting tool and workpiece relative to each other. c Axis definitions of the experimental setup. d Close view of the cutting setup 
Table 1 The parameters used in microturning tests

\begin{tabular}{lll}
\hline Cutting speed $(\mathrm{m} / \mathrm{min})$ & Depth of cut $(\mu \mathrm{m})$ & Feed rate $(\mu \mathrm{m} / \mathrm{rev})$ \\
\hline 150 & 40 & $0.5,1,2.5,5,10,20$ \\
300 & 40 & \\
500 & 65 & \\
\hline
\end{tabular}

The expressions given in Eqs. (18, 19 and 20) allow us to estimate the cutting force components in the coordinate system XYZ using the cutting parameters $\left(f\right.$ and $\left.a_{p}\right)$, tool geometry ( $\kappa_{r}$ and $R_{\varepsilon}$ ), and cutting force coefficients for a particular tool-workpiece pair. To calculate the cutting force components from Eqs. (18, 19 and 20), the cutting force and edge force coefficients must be known.

\section{Material and method}

\subsection{Cutting test setup}

To obtain the cutting force coefficients used in the mechanistic model, semi-orthogonal microturning experiments were performed. In the cutting experiments, the cutting speed and depth of cut were kept constant and feed rates were changed. To determine the effects of cutting speed and depth of cut on the cutting force coefficients, additional tests were carried out in different series. A specially designed high-speed and high precision test setup is used for the microturning tests. The whole system is fixed on a vibration isolated table (Fig. 2a). The repeatability of the axes used in the test setup is $1.5 \mu \mathrm{m}$ and the maximum spindle speed is $60,000 \mathrm{rpm}$. The spindle has a pneumatic tool clamping system and the workpiece is fixed by using collets of suitable diameter instead of the cutting tool (Fig. 2b). The feed rate of the workpiece is controlled by the $Z$-axis, and the depth of the cut is controlled by the $Y$-axis (Fig. 2c). The cutting tool and the tool holder are fixed on the dynamometer. The cutting forces were measured using a Kistler MiniDyn 9119A1 three-component dynamometer with its charge amplifier (Type 5070). Dynoware software was used to analyze the cutting force data. The sampling rate of the cutting force measurements was $12.5 \mathrm{kHz}(2 \mathrm{~d})$. During the experiments, a USB microscope with 50-800 $\times$ magnification was used to better observe the cutting zone more clearly.
A new cutting tool was used in each test to ensure that the cutting force values were not affected by tool wear. The cutting tests were repeated at least three times for each cutting parameter. A titanium specimen with a diameter of $10 \mathrm{~mm}$ was used to perform the cutting test. The cutting parameters used in microturning tests are given in Table 1. Different cutting parameters were used to validate the created model. $V_{c}=100,230,410 \mathrm{~m} / \mathrm{min}, a_{p}=30,50$, and $90 \mu \mathrm{m}$ and $f=4$, 7.5 and $12.5 \mu \mathrm{m} / \mathrm{rev}$ were used in the validation experiments. The tests were carried out under dry-cutting conditions. After the validation tests, the variation of the cutting forces over a wide range of cutting parameters was obtained by using the generated mechanistic model.

\subsection{Cutting tool and workpiece material}

In this study, Ti6Al4V alloy, which is widely used in the biomedical sector and dental implants and has been the subject of numerous studies due to its excellent mechanical properties, was chosen as the workpiece. The chemical composition of the Ti6Al4V alloy used is given in Table 2. The titanium alloy was supplied from Baoji First Titanium Industry Co., Ltd. and the comparison of the alloy produced with the ASTM B348 standard is also presented in Table 3. The mechanical properties of the alloy are also given in Table 2. In the cutting process, AlTiN-coated cutting tool manufactured by Kennametal was used for the cutting process. ISO Code of the cutting tool is TDHB07T12S0. The edge radius of the cutting tool was measured as $R_{e}=7.25 \mu \mathrm{m}$ and the nose radius as $R_{\varepsilon}=40 \mu \mathrm{m}$ (Fig. 3a, b). The cutting edge angle of the cutting tool is $90^{\circ}$, the rake angle is $0^{\circ}$, and the clearance angle is $15^{\circ}$ (Fig. 3a). The other geometrical parameters of the cutting tool are shown in Fig. $3 \mathrm{c}$.

\subsection{Determination of cutting coefficients}

The method proposed by Armarego and Brown [33] is generally used to obtain the cutting force coefficients needed for the mechanistic modeling of the turning process (Eq. 21). According to this method, normal friction angle $\left(\beta_{n}\right)$, inclination angle (i), normal rake $\left(\gamma_{n}\right)$, and chip flow angle $(\eta)$ are needed to obtain the Ktc, Kfc, and Krc coefficients. Various methods have been proposed to calculate these angles [32-34]. Since the deformed chip thickness is very small in microturning, it becomes difficult to determine the chip ratio $\left(r_{c}\right)$ and then the shear angle. For this reason, in this study, the cutting force
Table 2 Mean chemical composition of Ti6Al4V bar (wt.\%)

\begin{tabular}{llllllllllll}
\hline Element & $\mathrm{Ti}$ & $\mathrm{Al}$ & $\mathrm{V}$ & $\mathrm{Cu}$ & $\mathrm{Mo}$ & $\mathrm{Fe}$ & $\mathrm{Mn}$ & $\mathrm{C}$ & $\mathrm{N}$ & $\mathrm{O}$ \\
\hline wt.\% & Balance & 6.40 & 4.16 & 0.01 & 0.01 & 0.161 & 0.01 & 0.028 & 0.017 & 0.154 \\
ASTM B348 & Balance & $5.5-6.75$ & $3.5-4.5$ & - & - & 0.4 & - & 0.08 & 0.05 & 0.2
\end{tabular}


Table 3 Mechanical properties of Ti6A14V bar

\begin{tabular}{lll}
\hline Property & ASTM B348 & Specimen \\
\hline Young modulus (GPa) & 113.8 & 114 \\
Tensile strength (MPa) & $>895$ & 1013 \\
Yield strength (MPa) & $>828$ & 938 \\
Elongation at break, (\%) & $>10$ & 13 \\
Density (g/cm $\left.{ }^{3}\right)$ & 4.4 & 4.42 \\
Hardness (HRC) & $33-36$ & 34 \\
\hline
\end{tabular}

values obtained from the microturning experiment were substituted in Eqs. (18, 19 and 20), and the cutting force coefficients were obtained.

$$
\begin{aligned}
& K_{t c}=\frac{\tau_{s}}{\sin \phi} \cdot \frac{\cos \left(\beta n-\gamma_{0}\right)+\tan (i) \cdot \tan (\eta) \cdot \sin \left(\beta_{n}\right)}{\sqrt{\cos ^{2}\left(\phi+\beta_{n}-\gamma_{0}\right)+\tan ^{2}(\eta) \cdot \sin ^{2}\left(\beta_{n}\right)}} \\
& K_{f c}=\frac{\tau_{s}}{\sin \phi \cdot \cos i} \cdot \frac{\sin \left(\beta_{n}-\gamma_{0}\right)}{\sqrt{\cos ^{2}\left(\phi+\beta_{n}-\gamma_{0}\right)+\tan ^{2}(\eta) \cdot \sin ^{2}\left(\beta_{n}\right)}}
\end{aligned}
$$

$K_{r c}=\frac{\tau_{s}}{\sin \phi} \cdot \frac{\cos \left(\beta_{n}-\gamma_{0}\right) \cdot \tan (i)-\tan (\eta) \cdot \sin \left(\beta_{n}\right)}{\sqrt{\cos ^{2}\left(\phi+\beta_{n}-\gamma_{0}\right)+\tan ^{2}(\eta) \cdot \sin ^{2}\left(\beta_{n}\right)}}$

In order to calculate both cutting and edge force coefficients, the expressions in Eqs. (18, 19 and 20) are rearranged as follows. The cutting and edge force coefficients given in Eqs. (18, 19 and 20) are dependent on $\theta$. Besides, if cutting and edge coefficients are considered independents of $\theta$, they can be pulled out of the integral, giving place to the expressions in Eqs. (22, 23 and 24) [31].

$F_{x e x p}=K_{t e} G_{t x}+K_{t c} Z_{t x}$

$F_{\text {yexp }}=K_{f e} G_{f y}+K_{r e} G_{r y}+K_{f c} Z_{f y}+K_{r c} Z_{r y}$

$F_{z \exp }=K_{f e} G_{f z}+K_{r e} G_{r z}+K_{f c} Z_{f z}+K_{r c} Z_{r z}$

where $F_{x \exp }, F_{y \exp }$, and $F_{z \exp }$ on the left side of the equation represent the cutting forces obtained during microturning. Other expressions $\left(G_{i j}\right.$ and $\left.Z_{i j}\right)$ given in the equation depend only on the tool geometry and cutting conditions and are given in Eq. (23). $\theta_{1}$ and $\theta_{2}$ given in Eq. (23) are the angle values showing the integral limits and are given in Eq. (8).
Fig. 3 Geometric properties of the cutting tool used in microturning tests
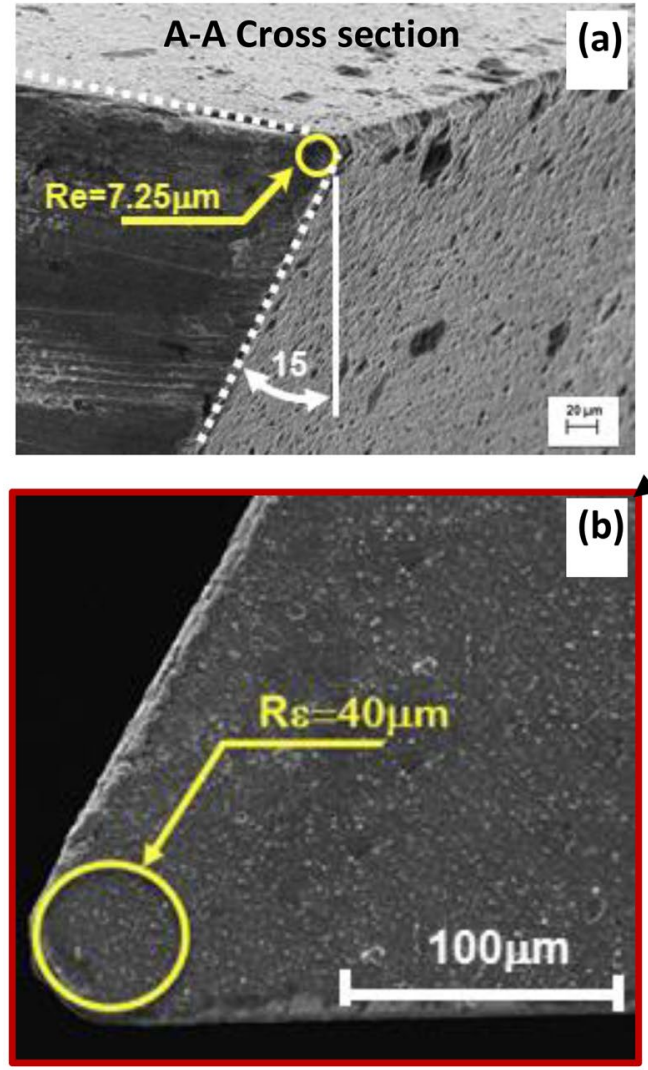
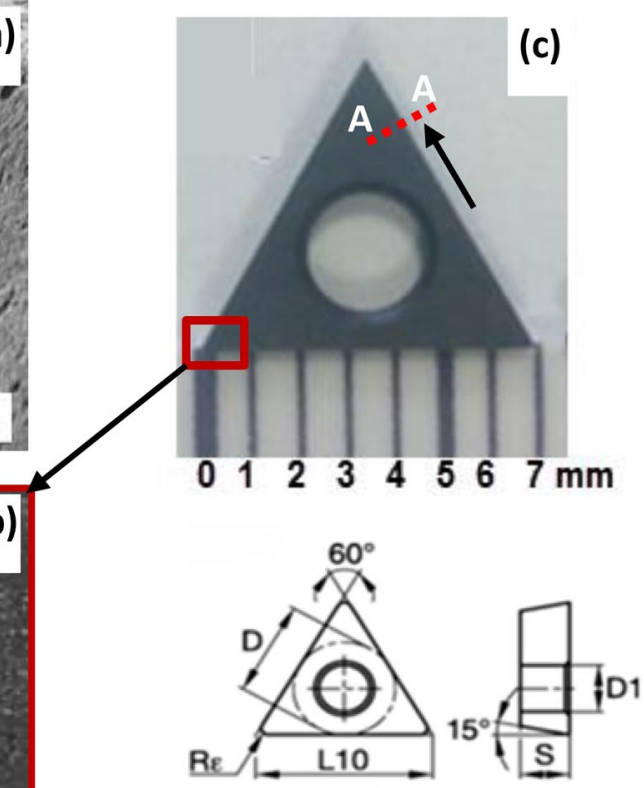

$$
\begin{aligned}
& \mathrm{L} 10=6.95 \mathrm{~mm} \\
& \mathrm{R} \varepsilon=40 \mu \mathrm{m} \\
& \mathrm{S}=1,18 \mathrm{~mm} \\
& D 1=2.39 \mathrm{~mm} \\
& D=3.42 \mathrm{~mm}
\end{aligned}
$$


$G_{f z}=\sin \kappa_{r} L_{I}+\int_{\theta_{1}}^{\theta_{2}} \sin \left(\theta-\frac{\pi}{2}\right) R_{\varepsilon} d \theta ;$
$G_{r z}=-\cos \kappa_{r} L_{I}-\int_{\theta_{1}}^{\theta_{2}} \cos \left(\theta-\frac{\pi}{2}\right) R_{\varepsilon} d \theta ;$

$G_{f y}=\cos \kappa_{r} L_{I}+\int_{\theta_{1}}^{\theta_{2}} \cos \left(\theta-\frac{\pi}{2}\right) R_{\varepsilon} d \theta ;$

$G_{r y}=\sin \kappa_{r} L_{I}+\int_{\theta_{1}}^{\theta_{2}} \sin \left(\theta-\frac{\pi}{2}\right) R_{\varepsilon} d \theta ;$

$Z_{f z}=\sin \kappa_{r} A_{I}+\int_{\theta_{1}}^{\theta_{2}} \sin \left(\theta-\frac{\pi}{2}\right) h(\theta) R_{\varepsilon} d \theta ;$

$Z_{r z}=-\cos \kappa_{r} A_{I}-\int_{\theta_{1}}^{\theta_{2}} \cos \left(\theta-\frac{\pi}{2}\right) h(\theta) R_{\varepsilon} d \theta$;

$Z_{f y}=\cos _{r} A_{I}+\int_{\theta_{1}}^{\theta_{2}} \cos \left(\theta-\frac{\pi}{2}\right) h(\theta) R_{\varepsilon} d \theta$;

$Z_{r y}=\sin _{r} A_{I}+\int_{\theta_{1}}^{\theta_{2}} \sin \left(\theta-\frac{\pi}{2}\right) h(\theta) R_{\varepsilon} d \theta ;$

$G_{t x}=L_{I}+\int_{\theta_{1}}^{\theta_{2}} R_{\varepsilon} d \theta$

$Z_{t x}=A_{I}+\int_{\theta_{1}}^{\theta_{2}} h(\theta) R_{\varepsilon} d \theta$

After calculating the $G_{i j}$ and $Z_{i j}$ terms in Eqs. $(23,24)$ was used to determine the cutting force coefficients for each set of experiments [35]. The solution of Eq. (24) was carried out by the least-squares method and $K_{i j}$ coefficients were obtained directly from microturning experiments. $F_{x 1}, \ldots, F_{x n} ; F_{y 1}, \ldots, F_{y n} ; F_{z 1}, \ldots, F_{z n}$, given in Eq. (24) are the average values of the cutting force components measured during microturning experiments. In order to obtain the cutting and edge force coefficients, 24 experiments were carried out using the cutting parameters given in Table $1 . K$ coefficients were obtained by using the obtained average cutting force components in Eq. (24).

$$
\begin{gathered}
{\left[\begin{array}{c}
F_{y 1} \\
\vdots \\
\vdots \\
F_{y n}
\end{array}\right]_{E x p}=\left[\begin{array}{cccc}
G_{f y 1} & G_{r y 1} & Z_{f y 1} & Z_{r y 1} \\
\cdot & \cdot & \cdot & \cdot \\
\cdot & \cdot & \cdot & \cdot \\
\cdot & \cdot & \cdot & \cdot \\
G_{f y n} & G_{r y n} & Z_{f y n} & Z_{r y n}
\end{array}\right] \cdot\left[\begin{array}{c}
k_{f e} \\
k_{r e} \\
k_{f c} \\
k_{r c}
\end{array}\right]} \\
{\left[\begin{array}{c}
F_{z 1} \\
\vdots \\
\vdots \\
F_{z n}
\end{array}\right]_{E x p}=\left[\begin{array}{cccc}
G_{f z 1} & G_{r z 1} & Z_{f z 1} & Z_{r z 1} \\
\cdot & \cdot & \cdot & \cdot \\
\cdot & \cdot & \cdot & \cdot \\
\cdot & \cdot & \cdot & \cdot \\
G_{f z n} & G_{r z n} & Z_{f z n} & Z_{r z n}
\end{array}\right] \cdot\left[\begin{array}{c}
k_{f e} \\
k_{r e} \\
k_{f c} \\
k_{r c}
\end{array}\right]}
\end{gathered}
$$

$\left[\begin{array}{c}F_{x 1} \\ \vdots \\ \vdots \\ F_{x n}\end{array}\right]_{E x p}=\left[\begin{array}{cc}G_{t x 1} & Z_{t x 1} \\ \cdot & \cdot \\ \cdot & \cdot \\ \cdot & \cdot \\ G_{t x n} & Z_{t x n}\end{array}\right] \cdot\left[\begin{array}{c}k_{t e} \\ k_{t c}\end{array}\right]$

\section{Results and discussion}

\subsection{Cutting test results}

In order to determine the cutting force values to be used in the mechanistic modeling, microturning experiments were carried out for different cutting parameters. The variation in cutting forces depending on the different depth of cut, cutting speed, and feed rate is given in Fig. 4. As can be seen in Fig. 4, the cutting forces increase linearly with increasing feed rate. It is possible to say that the $F_{x}$ (tangential direction) force and $F_{z}$ (feed direction) force increase linearly with increasing depth of cut (Fig. $4 \mathrm{a}-\mathrm{c}$ ). However, it is difficult to say that there is such a tendency in the $F_{y}$ (radial direction) force (Fig. 4b). Increasing cutting speed also contributes to the reduction of cutting forces. This situation is observed more clearly especially in the $F_{z}$ force (Fig. 4f).

\subsection{Variation of cutting and edge force coefficients}

After the microturning tests, three cutting force components for different cutting speeds, feed, and depth of cut were obtained in the previous section (Fig. 4). By using Eq. (22, 23 and 24), the coefficients $K_{c}$ and $K_{e}$ were obtained depending on the cutting forces obtained from the experiments. This procedure was repeated for 

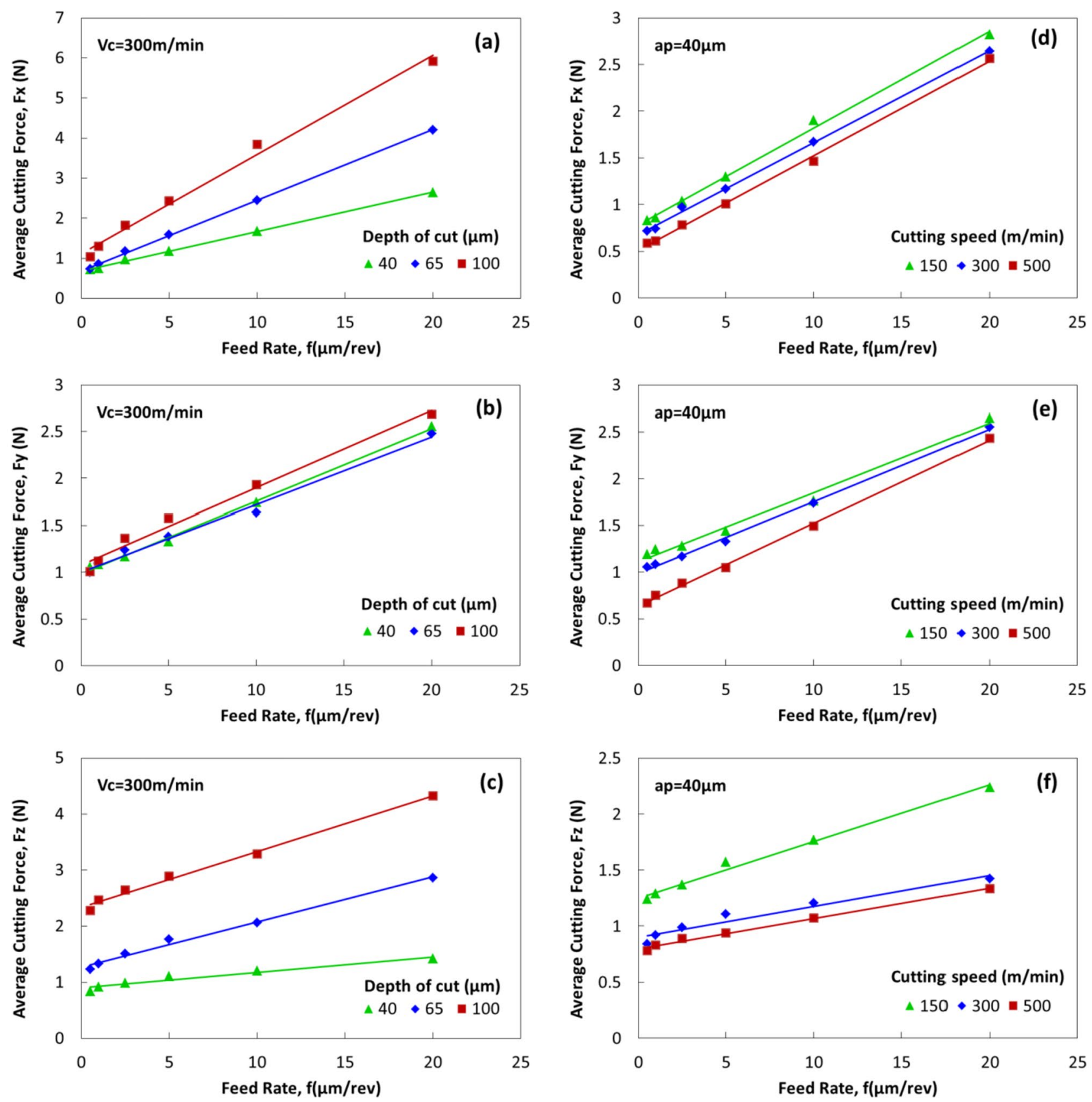

Fig. 4 Variation of the $F_{x}, F_{y}$, and $F_{z}$ forces obtained in microturning tests for different cutting parameters

different cutting speeds and depths of cut. The variations of cutting force coefficients as a function of cutting speed and depth of cut were determined (Table 4 shows the values of cutting force and edge force coefficients for different depths of cut). Figure 5 shows the variation of cutting force and edge force coefficients with a depth
Table 4 Cutting and edge force coefficients for different depth of cuts $\left(V_{C}=300 \mathrm{~m} / \mathrm{min}\right)$

\begin{tabular}{lllllll}
\hline$a_{p}(\mu \mathrm{m})$ & $K_{t c}\left(\mathrm{~N} / \mathrm{mm}^{2}\right)$ & $K_{f c}\left(\mathrm{~N} / \mathrm{mm}^{2}\right)$ & $K_{r c}\left(\mathrm{~N} / \mathrm{mm}^{2}\right)$ & $K_{t e}(\mathrm{~N} / \mathrm{mm})$ & $K_{f e}(\mathrm{~N} / \mathrm{mm})$ & $K_{r e}(\mathrm{~N} / \mathrm{mm})$ \\
\hline 40 & 2337 & 1466 & 801 & 13.3 & 32.2 & 4.6 \\
65 & 2301 & 1412 & 737 & 9.9 & 25.5 & 2.5 \\
100 & 2214 & 1201 & 401 & 9.4 & 24.6 & 2.6 \\
\hline
\end{tabular}


Fig. 5 Variation of cutting and edge force coefficients with a depth of cut $\left(V_{C}=300 \mathrm{~m} / \mathrm{min}\right)$
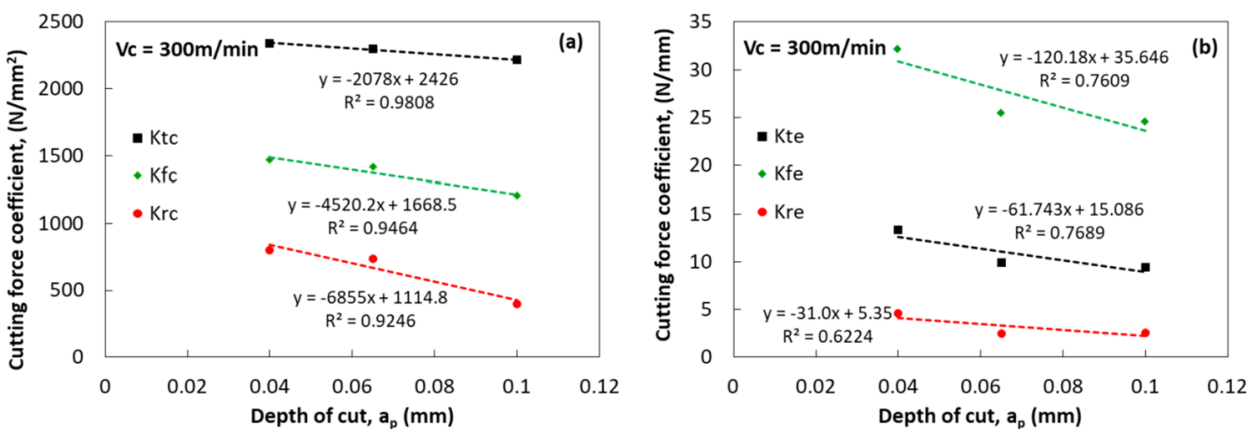

of cut. It can be observed that the force coefficients decrease linearly as the depth of cut increases. It can be said that the $R^{2}$ error for the cutting force coefficients is quite small. However, the $R^{2}$ error is higher for the edge cutting coefficients. There could be two reasons for this. The first is the dimensional difference in the edge radius of the cutting tool. The second is the tool wear that occurs during cutting. The first possibility is a problem that can arise from tool manufacturing, and it is not possible to manufacture all tools with the same geometry. To minimize the effects of the second possibility, a new cutting tool was used in each experiment. However, the contribution of the edge force coefficient to the total cutting force is lower.

Table 5 shows the values of the cutting and edge force coefficients obtained for different cutting speeds. Also, Fig. 6 shows the variation in the values of cutting and edge force coefficients as a function of cutting speed. It can be said that the values of $K_{f c}, K_{t c}$, and $K_{r c}$ decrease linearly with an increase in cutting speed. However, the variation of $K_{r c}$ with cutting speed is very limited, it can be said to remain constant. However, the edge force coefficients do not change significantly with cutting speed.

Multiple linear regression analysis was performed for the coefficients given in Tables 3 and 4 . Thus, the variation of force coefficients as a function of cutting speed and depth of cut is expressed by a linear equation. In some studies, the edge coefficients were assumed to be constant with the assumption that they change little with cutting speed and depth of cut [12]. In this study, a regression analysis was performed for the edge coefficients and an attempt was made to determine whether a linear relationship exists. For this purpose, first, the variation of six coefficients with $V_{c}$ and $a_{p}$ is expressed with a linear model as shown in Figs. 5 and 6.
It can be seen that the variation of cutting force coefficients with cutting speed and depth of cut fits very well with a linear model. The least-squares estimation method was used to develop the linear models. The models and analysis of variance indicators for the shear and edge coefficients are shown in Table 6. The P-value shows that the linear models for the three cutting coefficients $\left(K_{f c}, K_{r c}\right.$, and $K_{t c}$ ) are statistically significant. However, it is difficult to say that the $P$ value is statistically significant for the models obtained for the edge force coefficients (especially $K_{f e}$ and $\left.K_{r e}\right)$. The correlation coefficients $\left(R^{2}\right.$ and $R^{2}$ adj $)$ for the cutting force coefficients are higher than $70 \%$, which means that the relationship between the cutting coefficients and the cutting speed and depth of cut is adequately represented in the proposed models.

\subsection{Comparison of mechanistic model and experiment results}

A series of experimental tests were conducted to investigate the consistency of the proposed mechanistic models. The relationships for the cutting and edge coefficients, shown in Table 6, were introduced into the corresponding models together with the cutting conditions and the geometrical characteristics of the tool. In this way, the force values $F_{x}$, $F_{y}$, and $F_{z}$ were estimated for different cutting parameters. Then, these force values were compared with the experimental cutting forces obtained from the dynamometer. Figure 7 compares the results using different parameters from the cutting parameters used to determine the cutting and edge coefficients. In Fig. 7, the force results obtained for different feed values are compared with the model results. However, the cutting speed $\left(V_{c}=200 \mathrm{~m} / \mathrm{min}\right)$ and depth of cut $\left(a_{p}=50 \mu \mathrm{m}\right)$ used were also different from the parameters used in the
Table 5 Cutting and edge force coefficients for different cutting speeds $\left(\mathrm{a}_{\mathrm{p}}=40 \mu \mathrm{m}\right)$

\begin{tabular}{lllllll}
\hline $\mathrm{V}_{\mathrm{C}}(\mathrm{m} / \mathrm{min})$ & $\mathrm{K}_{\mathrm{tc}}\left(\mathrm{N} / \mathrm{mm}^{2}\right)$ & $\mathrm{K}_{\mathrm{fc}}\left(\mathrm{N} / \mathrm{mm}^{2}\right)$ & $\mathrm{K}_{\mathrm{rc}}\left(\mathrm{N} / \mathrm{mm}^{2}\right)$ & $\mathrm{K}_{\mathrm{te}}(\mathrm{N} / \mathrm{mm})$ & $\mathrm{K}_{\mathrm{fe}}(\mathrm{N} / \mathrm{mm})$ & $\mathrm{K}_{\mathrm{re}}(\mathrm{N} / \mathrm{mm})$ \\
\hline 150 & 2418 & 1604 & 821 & 13.8 & 35.7 & 4.6 \\
300 & 2337 & 1466 & 801 & 13.3 & 34.2 & 4.6 \\
500 & 2112 & 1377 & 642 & 12.9 & 33.9 & 3.8 \\
\hline
\end{tabular}


Fig. 6 Variation of cutting and edge force coefficients with cutting speeds $\left(a_{p}=40 \mu \mathrm{m}\right)$
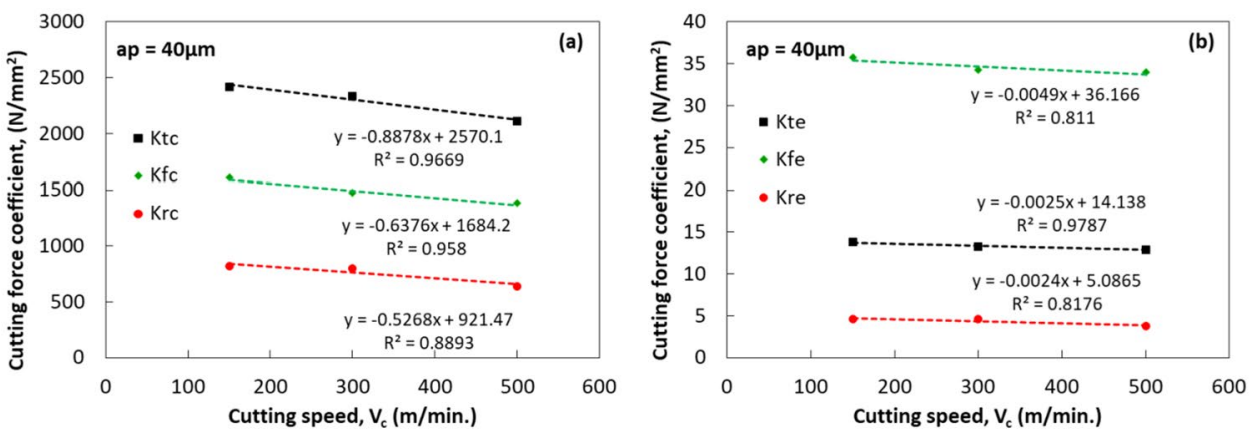

Table 6 Relationships and their regression analysis of the cutting and edge coefficients

\begin{tabular}{llll}
\hline Relationship for cutting and edge force coefficients & $R^{2}(\%)$ & $R_{\text {adj }}^{2}(\%)$ & P value \\
\hline$K_{f e}=41.25-0.0038 \cdot V c-0.1698 \cdot a_{p}$ & 79.0 & 58.0 & 0.210 \\
$K_{r e}=6.18-0.00224 \cdot V c-0.0328 \cdot a_{p}$ & 74.7 & 49.3 & 0.253 \\
$K_{t e}=16.65-0.00232 \cdot V c-0.0714 \cdot a_{p}$ & 84.7 & 69.4 & 0.153 \\
$K_{f c}=1882-0.643 \cdot V c-4.75 \cdot a_{p}$ & 97.2 & 94.4 & 0.028 \\
$K_{r c}=1007-0.382 \cdot V c-5.16 \cdot a_{p}$ & 87.9 & 75.8 & 0.012 \\
$K_{t c}=2632-0.892 \cdot V c-1.398 \cdot a_{p}$ & 95.3 & 90.6 & 0.047 \\
\hline
\end{tabular}
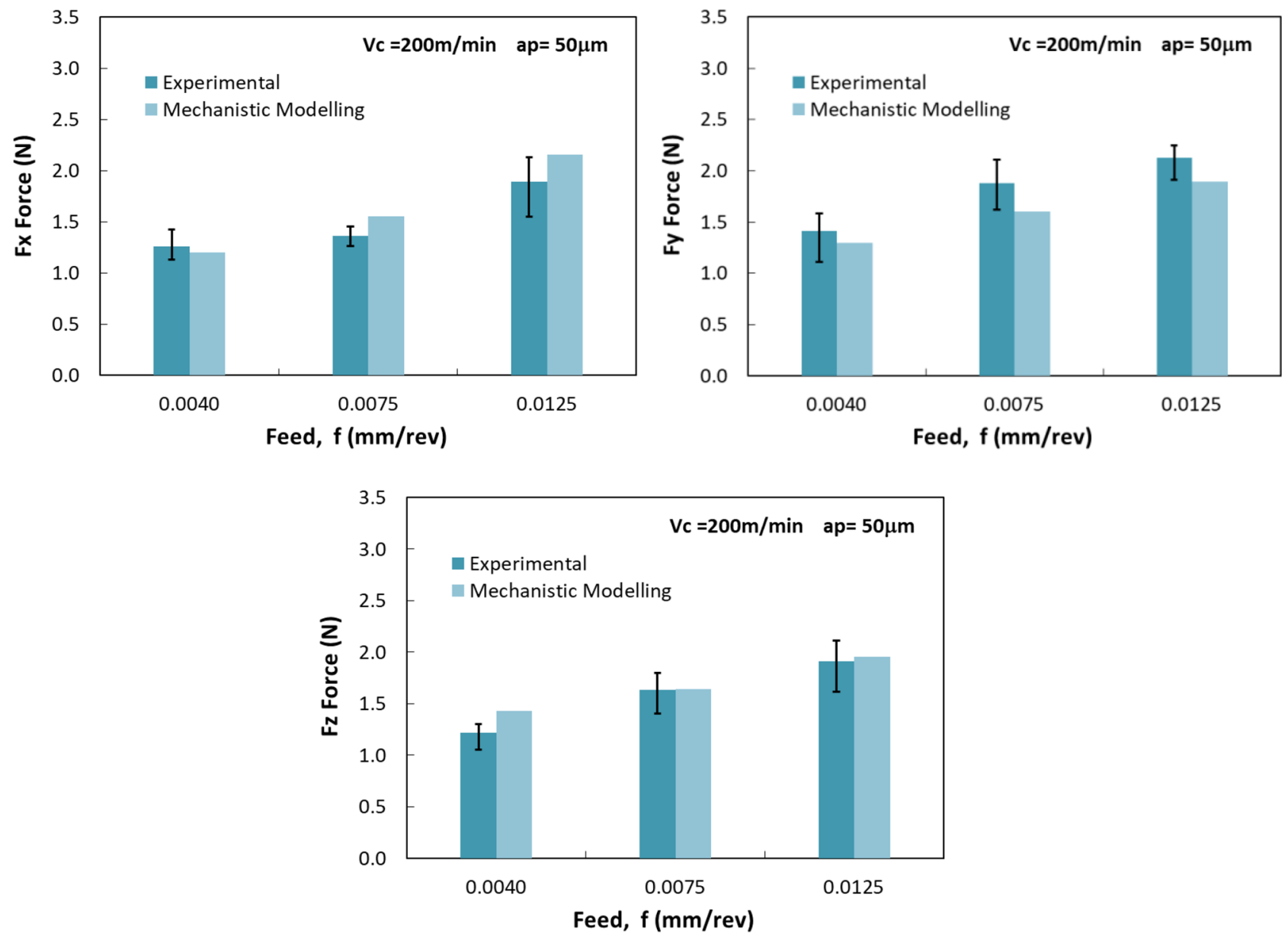

Fig. 7 Comparison of test results and mechanistic model results for different feed rate values 

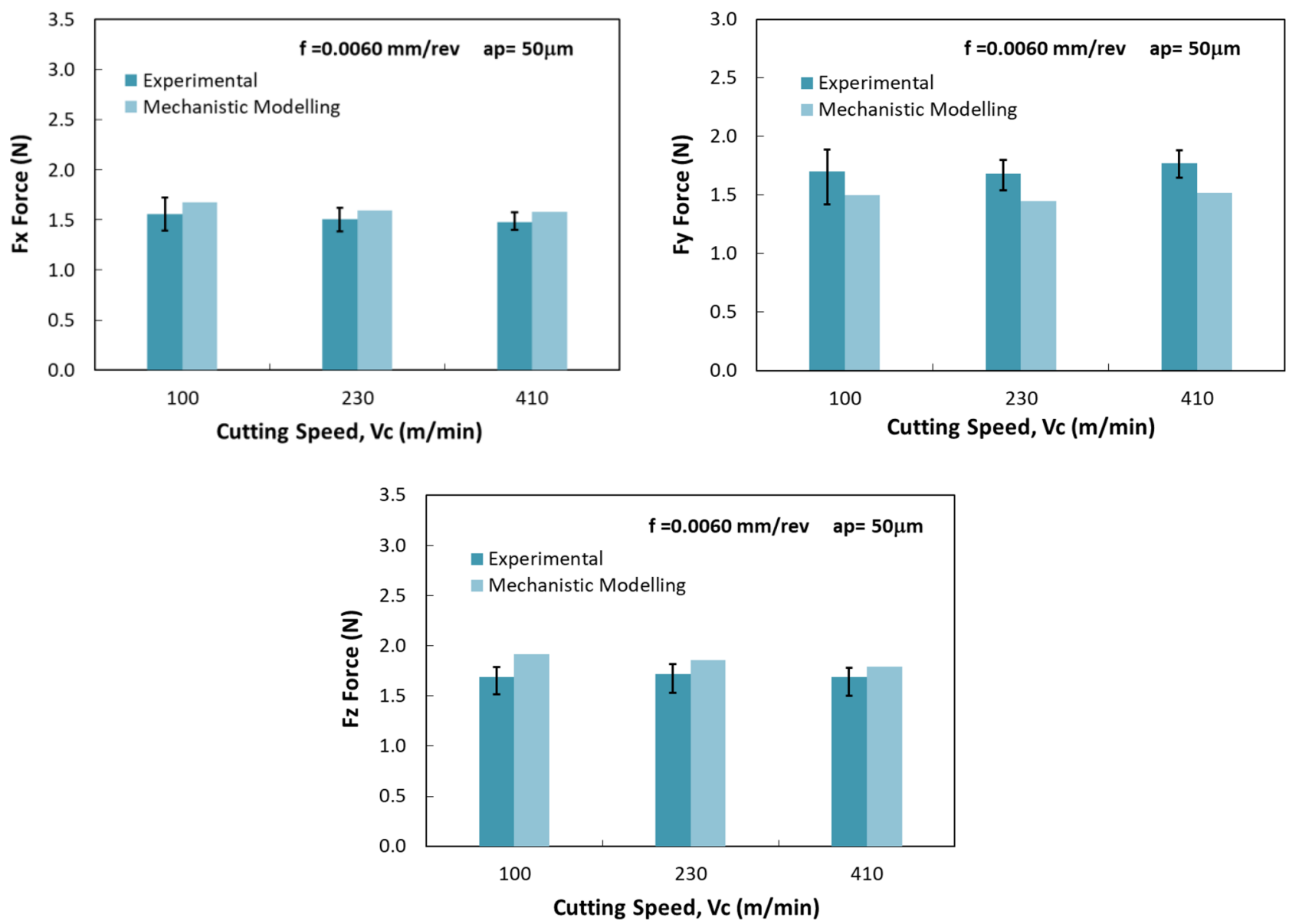

Fig. 8 Comparison of test results and mechanistic model results for different cutting speed values

model. It is aimed to show how well the results obtained from the model for different cutting parameters are in agreement with the experimental one. As can be seen from Fig. 7, the cutting forces increase with increasing feed rate. Increasing feed rate causes the chip cross section removed per unit time to increase, which in turn increases the cutting forces. Comparing the model and experimental results, it can be said that acceptable convergence has taken place. The maximum error (24\%) was obtained for $0.0075 \mathrm{~mm} /$ rev at $F_{y}$ force, while the minimum error was obtained at $F_{z}$ force. The reason for the maximum error; the linear model is used in the regression analysis of $\mathrm{K}$ coefficients obtained as a function of cutting speed and depth of cut. Since a linear regression based on the depth of cut and the cutting speed means that the amount of error occurring in both cases is multiplied, the amount of error has also increased. As can be seen in Fig. 7, the model and experimental results are close to each other in the feed value $(f=4 \mu \mathrm{m} / \mathrm{rev})$ which is smaller than the tool edge radius $\left(R_{e}=7.25 \mu \mathrm{m}\right)$. Similarly, it is possible to say that the experimental and mechanistic results obtained for $f=12.5 \mu \mathrm{m} / \mathrm{rev}$ are compatible with each other.
To demonstrate the validity of the model created, experiments were also conducted at different cutting speeds and the results were compared with the mechanistic model (Fig. 8). As can be seen in Fig. 8, different parameters from the cutting parameters used in the creation of the mechanistic model were used. With the increasing cutting speed, a decrease is observed in all three cutting forces. However, this decrease is at very low levels. This decrease may be the result of thermal softening with increasing temperature in the cutting zone. High cutting speed results in tool wear, while low cutting speed causes built-up-edge. It should be noted that both these conditions affect the cutting forces. Therefore, the increase in cutting speed may not be the only reason for the decrease here. In some studies, while the cutting forces increased with increasing cutting speed [36], it remained constant in some studies [37]. The thermal properties of the Ti6Al4V alloy as well as the tendency to chemically bond with the carbide tool can lead to different results. It can be seen that the difference between the experimental and mechanistic models decreases with increasing cutting speed for the $F_{x}$ and $F_{z}$ forces. However, this is not true 

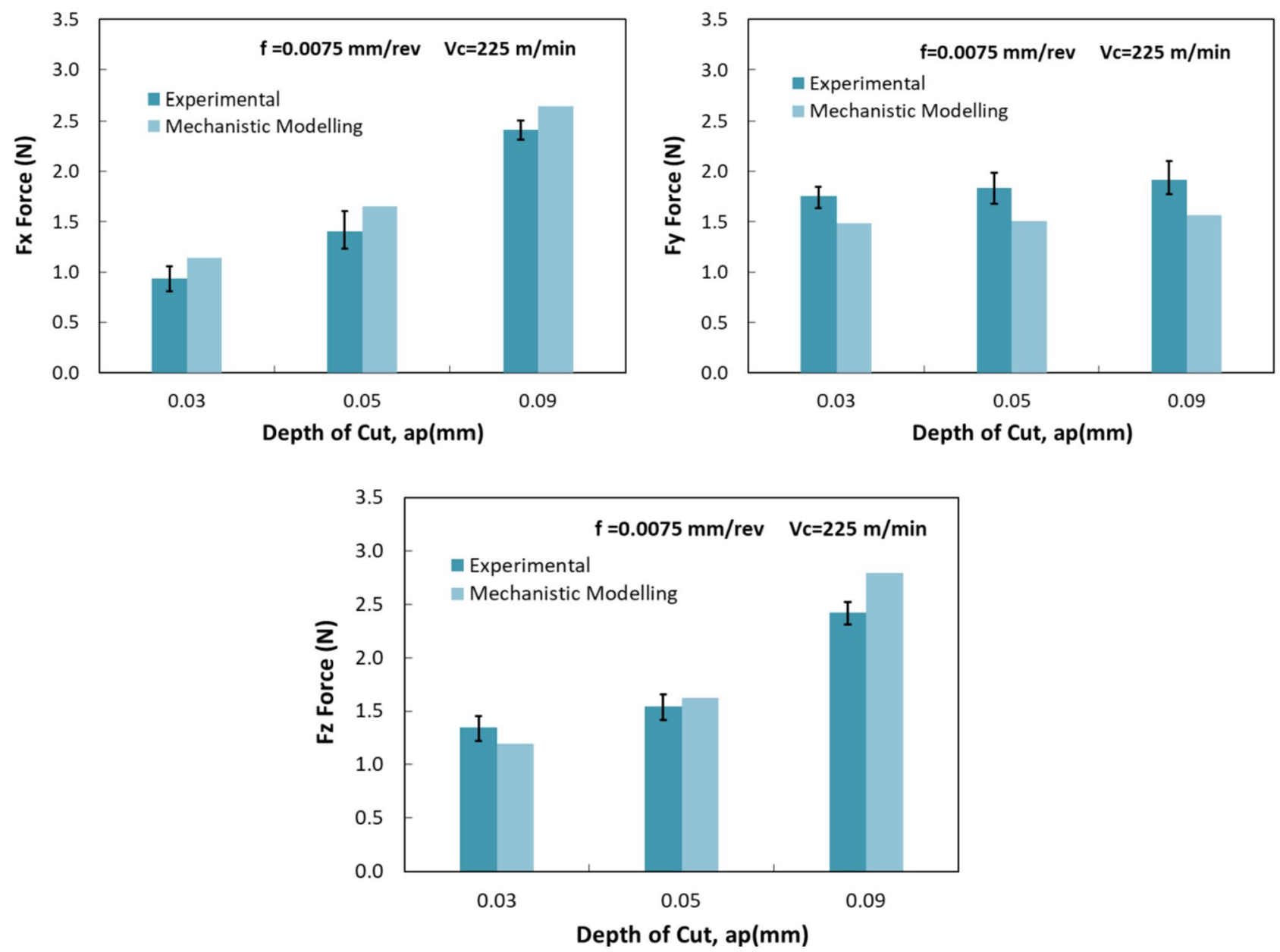

Fig. 9 Comparison of test results and mechanistic model results for different depths of cut values

for the $F_{y}$ forces. While the error for the $F_{x}$ and $F_{z}$ forces is $7.5 \%$ on average, the error for the $F_{y}$ forces is about $16.4 \%$. However, it can be said that the error between the predicted cutting forces and the experimental results is at an acceptable level. In studies where mechanistic modeling techniques are used, the difference between experiment and modeling varies from 16 to $26 \%[12,13]$.

In microturning, feed rate and depth of cut are important for chip formation. In the cutting process with a very low feed rate $\left(f<<R_{e}\right)$ and shallow depth of cut $\left(a_{p}<<R_{e}\right)$, the ploughing mechanism is more dominant than the slip. For this reason, in this study, the mechanistic model was verified by conducting experiments at different depths of cut. Figure 9 shows the comparison of cutting forces obtained for different depths of cut. The maximum error occurred at $0.09 \mathrm{~mm}$ depth of cut and $21.3 \%$ for $F_{y}$ force. The maximum error for $F_{x}$ forces is $12 \%$. It can be seen that $F_{y}$ forces do not change with increasing depth of cut. Since $F_{y}$ force is the force in the radial direction, it was not affected by increasing the depth of cut. It can be seen that the difference between the experiment and modeling for $F_{z}$ force increases with the depth of cut $\left(a_{p}=30 \mu \mathrm{m}\right)$, which is smaller than the nose radius.

\section{Effect of cutting parameters on cutting forces}

In the previous section, the validation of the mechanistic model used was done. This section aims to reveal the effect of cutting parameters on cutting force in high-speed microturning process with $3 \mathrm{D}$ variation graphs. The variation in cutting forces was obtained by using a wide range of cutting speed $(100-500 \mathrm{~m} / \mathrm{min})$, depth of cut $(30-90 \mu \mathrm{m})$, and feed rate $(0.5-20 \mu \mathrm{m} / \mathrm{rev})$. In Fig. 10, the variation of cutting forces occurring during high-speed microturning is given. In Fig. 10a, c and e, the variation of all three cutting forces depending on the depth of cut and feed rate is given. Increasing depth of cut and feed rate increase the chip crosssection . Increasing chip cross-section $\left(a_{p} x_{f}\right)$ caused the $F_{x}$ force to increase 2.4 times and the $F_{z}$ force approximately 4.6 times. The increase in $F_{y}$ force is only about $35 \%$. From this 

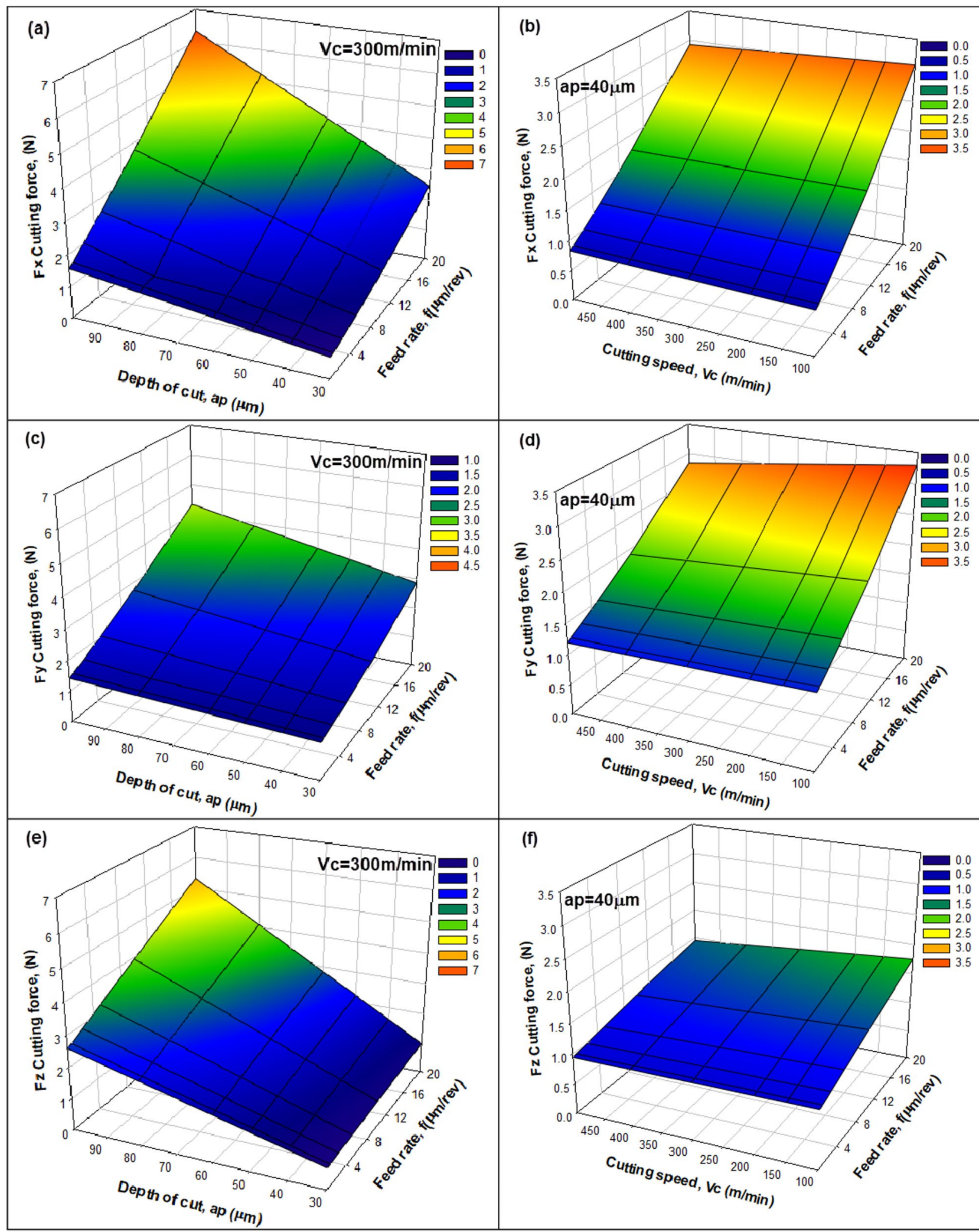

Fig. 10 Effect of cutting parameters on cutting forces 
point of view, it can be concluded that the increased chip cross-section in the microturning process affects the cutting force in the feed direction more. The $F_{y}$ force is particularly affected by the feed value, and at low feed rates $(\leq 8 \mu \mathrm{m} / \mathrm{rev})$ increasing depth of cut has little effect. Figure 10b, d and $\mathrm{f}$ show the effect of cutting speed and feed rate on cutting forces. Increasing cutting speed causes a decrease in cutting forces. This reduction is approximately $5 \%$ for the $F_{x}$ force, $14 \%$ for the $F_{y}$ force, and $17 \%$ for the $F_{z}$ force for $f=20 \mu \mathrm{m} /$ rev. However, at the minimum feed rate $(f=0.5 \mu \mathrm{m} / \mathrm{rev})$, the $F_{y}$ and $F_{z}$ forces decreased by approximately $3.5 \%$, while the $F_{x}$ force increased by $10 \%$.

\section{Conclusion}

A mechanistic model considering the nose radius is proposed to estimate the cutting forces during the high-speed microturning process. For the Ti6Al4V alloy, much higher cutting speeds than those used in conventional turning are used. In addition, multilinear regression analysis was performed in the study, and the mechanistic model was generalized depending on the cutting speed and depth of cut. It is possible to rank the obtained results as follows.

- The effect of cutting speed and depth of cut was expressed with a single linear equation by performing multiple linear regression analysis. Thus, the proposed model can be used for different cutting parameters.

- The coefficients for cutting and edge force coefficients are expressed using a linear model. While the $R^{2}$ value of the cutting force coefficients is more than $85 \%$, the $R^{2}$ value for the edge force coefficients is about $70 \%$.

- Validation tests were conducted both within and outside the range of cutting conditions used to determine the force coefficients.

- From the validation tests, it can be concluded that the model has good predictive power. The maximum error between experiment and model is $24 \%$ while the minimum error is $3 \%$.

It has been determined that increasing the depth of cut and feed value causes a linear increase in $F_{x}$ and $F_{z}$ forces, while the increase in depth of cut does not cause any change in $F_{y}$ force.

- Although cutting speed causes a small decrease in cutting forces, this variation is around $5 \%$ on average.

Author contribution All the authors have contributed equally to the production of the present paper.

Data availability All data that support the findings of this study are available from the corresponding author upon reasonable request.

\section{Declarations}

Conflict of interest The authors declare no competing interests.

Open Access This article is licensed under a Creative Commons Attribution 4.0 International License, which permits use, sharing, adaptation, distribution and reproduction in any medium or format, as long as you give appropriate credit to the original author(s) and the source, provide a link to the Creative Commons licence, and indicate if changes were made. The images or other third party material in this article are included in the article's Creative Commons licence, unless indicated otherwise in a credit line to the material. If material is not included in the article's Creative Commons licence and your intended use is not permitted by statutory regulation or exceeds the permitted use, you will need to obtain permission directly from the copyright holder. To view a copy of this licence, visit http://creativecommons.org/licenses/by/4.0/.

\section{References}

1. Cheng K, Huo D (eds) (2013) Micro cutting: fundamentals and applications. Wiley, Chichester

2. Boswell B, Islam MN, Davies IJ (2018) A review of micromechanical cutting. Int J Adv Manuf Technol. https://doi.org/10. 1007/s00170-017-0912-y

3. Lim HS, Kumar AS, Rahman M (2002) Improvement of form accuracy in hybrid machining of microstructures. J Electron Mater 31(10): 1032-1038

4. Lu Z, Yoneyama T (1999) Micro cutting in the micro lathe turning system. Int J Mach Tools Manuf 39(7):1171-1183

5. Rahman MA, Rahman M, Kumar AS, Lim HS, Asad ABMA (2006) Development of micropin fabrication process using tool based micromachining. Int J Adv Manuf Technol 27(9-10):939-944

6. Özel T (2009) Computational modelling of 3D turning: Influence of edge micro-geometry on forces, stresses, friction and tool wear in PcBN tooling. J Mater Process Technol 209:5167-5177. https:// doi.org/10.1016/j.jmatprotec.2009.03.002

7. Jagadesh T, Samuel GL (2017) Finite element simulations of micro turning of Ti-6Al-4V using PCD and coated carbide tools. J Inst Eng Ser C 98:5-15. https://doi.org/10.1007/s40032-016-0271-8

8. Pimenov DY, Guzeev VI, Koshin AA (2011) Influence of cutting conditions on the stress at tool's rear surface. Russ Eng Res 31:1151-1155. https://doi.org/10.3103/S1068798X11110207

9. Ucun İ, Aslantas K, Bedir F (2016) Finite element modeling of micro-milling: Numerical simulation and experimental validation. Mach Sci Technol 20:148-172. https://doi.org/10.1080/10910344. 2016.1147650

10. Ucun İ, Aslantas K, Özkaya E, Cicek A (2017) 3D numerical modelling of micro-milling process of Ti6Al4V alloy and experimental validation. Adv Mater Process Technol. https://doi.org/10. 1080/2374068X.2016.1247343

11. Uçak N, Çiçek A, Oezkaya E, Aslantas K (2019) Finite element simulations of cutting force, torque, and temperature in drilling of Inconel 718. Procedia CIRP 82:47-52. https://doi.org/10.1016/j. procir.2019.03.277

12. Pimenov DY, Guzeev VI (2017) Mathematical model of plowing forces to account for flank wear using FME modeling for orthogonal cutting scheme. Int J Adv Manuf Technol 89:3149-3159

13. Orra K, Choudhury SK (2018) Mechanistic modelling for predicting cutting forces in machining considering effect of tool nose radius on chip formation and tool wear land. Int J Mech Sci 142-143:255-268. https://doi.org/10.1016/j.ijmecsci.2018.05.004 
14. Wojciechowski S, Matuszak M, Powałka B et al (2019) Prediction of cutting forces during micro end milling considering chip thickness accumulation. Int J Mach Tools Manuf 147:103466. https:// doi.org/10.1016/j.ijmachtools.2019.103466

15. Sahoo P, Patra K, Singh VK et al (2020) Influences of TiAlN coating and limiting angles of flutes on prediction of cutting forces and dynamic stability in micro milling of die steel (P-20). J Mater Process Technol 278:116500. https://doi.org/10.1016/j.jmatprotec. 2019.116500

16. Jagadesh T, Samuel GL (2015) Mechanistic and finite element model for prediction of cutting forces during micro-turning of titanium alloy. Mach Sci Technol 19:593-629. https://doi.org/10. 1080/10910344.2015.1085318

17. Wang Y, Zou B, Huang C (2019) Tool wear mechanisms and micro-channels quality in micro-machining of Ti-6Al-4V alloy using the $\mathrm{Ti}(\mathrm{C} 7 \mathrm{~N} 3)$-based cermet micro-mills. Tribol Int 134:60-76

18. Guzeev VI, Pimenov DY (2011) Cutting force in face milling with tool wear. Russ Eng Res 31:989-993. https://doi.org/10. 3103/S1068798X11090139

19. Aslantas K, Alatrushi LKH, Bedir F et al (2020) An experimental analysis of minimum chip thickness in micro-milling of two different titanium alloys. Proc Inst Mech Eng Part B J Eng Manuf 234:1486-1498

20. Oliaei SNB, Karpat Y (2017) Built-up edge effects on process outputs of titanium alloy micro milling. Precis Eng 49:305-315

21. Tan D-W, Chen Z-W, Wei W-X et al (2020) Wear behavior and mechanism of TiB2-based ceramic inserts in high-speed cutting of Ti6Al4V alloy. Ceram Int 46:8135-8144

22. Pradhan S, Singh S, Prakash C et al (2019) Investigation of machining characteristics of hard-to-machine Ti-6Al-4V-ELI alloy for biomedical applications. J Mater Res Technol 8:48494862. https://doi.org/10.1016/j.jmrt.2019.08.033

23. Aslantas K, Danish M, Hasçelik A et al (2020) investigations on surface roughness and toolwear characteristics in micro-turning of Ti-6Al-4V alloy. Materials (Basel). https://doi.org/10.3390/ ma13132998

24. Aslantas K, Çiçek A (2018) High speed turning of Ti6Al4V alloy in micro cutting conditions. Procedia CIRP 77:58-61

25. Azizur Rahman M, Rahman M, Senthil Kumar A, Lim HS (2005) CNC microturning: an application to miniaturization. Int J Mach Tools Manuf 45:631-639. https://doi.org/10.1016/j.ijmachtools. 2004.10.003
26. Lucca DA, Seo YW, Komanduri R (1993) Effect of tool edge geometry on energy dissipation in ultraprecision machining. CIRP Ann - Manuf Technol 42:83-86. https://doi.org/10.1016/S00078506(07)62397-X

27. Horváth R (2015) A new model for fine turning forces. Acta Polytech Hungarica 12. https://doi.org/10.12700/APH.12.7.2015.7.7

28. Hasçelik A, Aslantas K (2022) Determination of cutting force coefficients with mechanistic and numerical modelling in micro turning process. Gazi Üniv Mühendislik Mimarlık Fak Derg 37(1):235-246. https://doi.org/10.17341/gazimmfd.794462

29. Jin X, Altintas Y (2011) Slip-line field model of micro-cutting process with round tool edge effect. J Mater Process Technol 211:339-355. https://doi.org/10.1016/j.jmatprotec.2010.10.006

30. Shalaby MA, El Hakim MA, Veldhuis SC, Dosbaeva GK (2017) An investigation into the behavior of the cutting forces in precision turning. Int J Adv Manuf Technol 90:1605-1615. https://doi. org/10.1007/s00170-016-9465-8

31. Fernández-Abia AI, Barreiro J, López de Lacalle LN, MartínezPellitero S (2012) Behavior of austenitic stainless steels at high speed turning using specific force coefficients. Int J Adv Manuf Technol 62:505-515. https://doi.org/10.1007/s00170-011-3846-9

32. Altintas Y (2012) Manufacturing automation. In: Manufacturing Automation. Cambridge University Press, Cambridge

33. Armarego EJA, Brown RH (1969) The machining of metals. Prentice-Hall

34. Stabler GV (1964) The chip flow law and its consequences. Proceedings of 5th Machine Tool Design and Research Conference, 243-251

35. Fernández-Abia AI, García JB, de Lacalle LNL, Neto OP (2015). Estimation of cutting forces and tool wear using modified mechanistic models in high performance turning. (pp 49-107). https:// doi.org/10.1007/978-3-662-45088-8_3

36. Hou J, Zhou W, Duan H et al (2014) Influence of cutting speed on cutting force, flank temperature, and tool wear in end milling of Ti-6Al-4V alloy. Int J Adv Manuf Technol 70:1835-1845

37. Zheng K, Yang F, Zhang N et al (2020) Study on the cutting performance of micro textured tools on cutting Ti-6Al-4V titanium alloy. Micromachines 11:137

Publisher's Note Springer Nature remains neutral with regard to jurisdictional claims in published maps and institutional affiliations. 